\title{
Take-off angle dependent x-ray photoelectron spectroscopy, secondary ion mass spectrometry, and scanning electron microscopy for determining the thickness and composition of passivation layers on technical aluminum foils
}

\section{Citation for published version (APA):}

Gunter, P. L. J., Borg, H. J., Niemantsverdriet, J. W., \& Rheiter, H. J. H. (1992). Take-off angle dependent x-ray photoelectron spectroscopy, secondary ion mass spectrometry, and scanning electron microscopy for determining the thickness and composition of passivation layers on technical aluminum foils. Journal of Vacuum Science and Technology A: Vacuum, Surfaces, and Films, 10(4, Pt. 3), 2846-2851. https://doi.org/10.1116/1.577718

DOI:

10.1116/1.577718

Document status and date:

Published: 01/01/1992

\section{Document Version:}

Publisher's PDF, also known as Version of Record (includes final page, issue and volume numbers)

\section{Please check the document version of this publication:}

- A submitted manuscript is the version of the article upon submission and before peer-review. There can be important differences between the submitted version and the official published version of record. People interested in the research are advised to contact the author for the final version of the publication, or visit the $\mathrm{DOI}$ to the publisher's website.

- The final author version and the galley proof are versions of the publication after peer review.

- The final published version features the final layout of the paper including the volume, issue and page numbers.

Link to publication

\footnotetext{
General rights

- You may freely distribute the URL identifying the publication in the public portal. follow below link for the End User Agreement:

www.tue.nl/taverne

\author{
Take down policy \\ If you believe that this document breaches copyright please contact us at: \\ openaccess@tue.nl \\ providing details and we will investigate your claim.
}

Copyright and moral rights for the publications made accessible in the public portal are retained by the authors and/or other copyright owners and it is a condition of accessing publications that users recognise and abide by the legal requirements associated with these rights.

- Users may download and print one copy of any publication from the public portal for the purpose of private study or research.

- You may not further distribute the material or use it for any profit-making activity or commercial gain

If the publication is distributed under the terms of Article 25fa of the Dutch Copyright Act, indicated by the "Taverne" license above, please 
Take-off angle dependent x-ray photoelectron spectroscopy, secondary ion mass spectrometry, and scanning electron microscopy for determining the thickness and composition of passivation layers on technical aluminum foils

\author{
P. L. J. Gunter, H. J. Borg, and J. W. Niemantsverdriet ${ }^{a)}$ \\ Laboratory of Inorganic Chemistry and Catalysis, Eindhoven University of Technology, \\ $5600 \mathrm{MB}$ Eindhoven, The Netherlands \\ H. J. H. Rheiter \\ Océ Netherlands BV, 5900 MA Venlo, The Netherlands
}

(Received 3 October 1991; accepted 3 February 1992)

\begin{abstract}
Angle dependent $x$-ray photoelectron spectroscopy, static secondary ion mass spectrometry, and scanning electron microscopy have been used to investigate the effect of a cleaning procedure on the composition, morphology and thickness of passivation layers on technical aluminum foils. The results show that the cleaner, a solution of sodium carbonate, phosphate and surfactants, not only removes undesirable oil contaminations efficiently, but also etches the surface. Because magnesium-rich inclusions are etched at a faster rate than the surrounding aluminum, the foil acquires roughness on the scale of about $100 \mathrm{~nm}$, whereas at the same time the surface composition changes. In particular, small amounts of phosphate are deposited on the surface. All these factors are considered favorable for improved adhesion.
\end{abstract}

\section{INTRODUCTION}

Rolled aluminum foils can be used as a substrate for various types of organic overlayers. However, oil residues from the rolling stage in the fabrication of the foils have to be removed to improve the adhesive properties of the aluminum surface. An aqueous solution of sodium phosphates, sodium carbonate, and surfactants can be applied as cleaning agent. We used $\mathrm{x}$-ray photoelectron spectroscopy (XPS), seeondary ion mass spectrometry (SIMS), and scanning electron microscopy (SEM) to investigate the effect of this cleaner on the morphology, composition, and thickness of passivation layers on the aluminum. This forms essential information in choosing the contact time of foil and cleaner that results in optimum adhesive properties.

XPS is frequently used for determining the thickness of passivation layers on metals ${ }^{1}$ and in particular on aluminum. ${ }^{2-4}$ For an overlayer $o$ of thickness $d$ on a substrate $s$, the XPS intensity ratio is given by

$$
\frac{I_{o}}{I_{s}}=\frac{n_{o} \sigma_{o} \lambda_{o}\left(E_{o}\right)}{n_{s} \sigma_{s} \lambda_{s}\left(E_{s}\right)} \frac{1-\exp \left\{-d /\left[\lambda_{o}\left(E_{o}\right) \cos \theta\right]\right\}}{\exp \left\{-d /\left[\lambda_{o}\left(E_{s}\right) \cos \theta\right]\right\}} .
$$

Here $I_{o}$ and $I_{s}$ are the areas of peaks in the XPS spectrum characteristic for the overlayer and substrate, respectively. The symbols $n_{o}$ and $n_{s}$ denote the corresponding atomic concentrations and $\sigma_{o}$ and $\sigma_{s}$ the XPS cross sections. $\lambda_{o(s)}$ is the inelastic mean free path of electrons traveling through the overlayer (substrate); this parameter depends on the electron's kinetic energy: $E_{0}$ for electrons emitted in the overlayer, and $E_{s}$ for electrons emitted in the substrate. $\Theta$ is the off-axis angle measured from the surface normal and $d$ is the thickness of the overlayer. ${ }^{5}$ In case of passivation layers on aluminum, one can take the metallic part of an aluminum peak as the substrate peak and the oxidic part as the overlayer peak. In that case $E_{o}$ very nearly equals $E_{s}$ and $\mathrm{Eq}$. (1) reduces to

$$
\begin{aligned}
\frac{I_{\mathrm{Al}^{3}+}}{I_{\mathrm{Al}}}= & \frac{n_{\mathrm{Al}^{3}+\lambda_{\mathrm{A}^{3}}+(E)}}{n_{\mathrm{A} \lambda \lambda_{\mathrm{A} 1}(E)}} \\
& \times\left\{\exp \left[d /\left(\lambda_{\mathrm{Al}^{3}+}(E) \cos \theta\right)\right]-1\right\} .
\end{aligned}
$$

Strohmeier ${ }^{2-4}$ points out that a single measurement, i.e., with the detector at a fixed angle to the sample, is sufficient for determining the thickness of the aluminum oxide layer on aluminum foils. However, this is only safe if such layers are known to have a homogeneous composition and a uniform thickness. Non-uniform concentration profiles and, in particular, surface roughness cause serious deviations from Eqs. (1) and (2). In general, the intensity ratio varies less than predicted by these equations and the thickness $d$ determined from Eq. (2) becomes an ill-defined quantity. ${ }^{5,6}$ In our work we used angle dependent XPS to check the applicability of Eqs. (1) and (2) for the samples under investigation.

\section{EXPERIMENTAL}

The aluminum foils contained $4.5 \% \mathrm{Mg}$ in the form of inclusions of either $\mathrm{Mg}$ or $\mathrm{Mg}-\mathrm{Al}$ alloy, as well as traces of $\mathrm{Fe}, \mathrm{V}, \mathrm{Cr}$, and $\mathrm{Mn}$. In their preparation, the foils were rolled in a Sendzimir rolling machine, a process in which aliphatic oil is used. The processing oil was removed by a commercially available cleaner, consisting of sodium phosphates (approximately $50 \mathrm{wt} \%$ ), sodium carbonate ( 30 wt $\%)$ and surfactants $(20 \mathrm{wt} \%)$-the nature of which can not be disclosed for proprietary reasons-dissolved in water. The solution had a high $p \mathrm{H}$ of about 10 .

XPS spectra were measured with a VG Scientific ESCALAB 200 system, equipped with a monochromated 
Al $K \alpha$ source, a hemispherical analyzer with a five channel detector and a manipulator which allows for rotation of the sample with respect to the analyzer. Electrons are focused onto the analyzer by a three times magnifying input lens of a nominal $12^{\circ}$ cone acceptance angle. The pressure of the system while taking spectra was around $8 \times 10^{-10} \mathrm{mbar}$. All spectra were analyzed by the software of the VGS 5250 Data System. Samples were mounted on the stainless steel sample stubs by using tantalum masks.

The SIMS spectra were recorded with a Leybold SSM 200 quadrupole mass spectrometer system. The pressure was in the $10^{-9}$ mbar range. The differentially pumped argon (99.999\% pure, Messer Griesheim) ion gun (Leybold IQE 12-63) was operated at an energy of $5 \mathrm{keV}$ and a current density of $50 \mathrm{nA} / \mathrm{cm}^{2}$. The time to record both a positive and negative SIMS spectrum was $200 \mathrm{~s}$, so that the total ion dose was $5 \times 10^{13}$ ions $/ \mathrm{cm}^{2}$, which is about the static limit. The samples were mounted on the sample rod using tantalum masks; no tantalum signals were detected during the measurements.

Scanning electron images were obtained with a JEOL 840 electron microscope, with a primary electron energy of $5 \mathrm{keV}$, a beam current of $0.3 \mathrm{nA}$, a magnification of $3000 \times$ and a base pressure of $10^{-6} \mathrm{mbar}$. Prior to measurement, the samples were covered with a layer of $10 \mathrm{~nm} \mathrm{Au}$ from an evaporation source, in order to increase secondary electron emission.

\section{RESULTS}

\section{A. XPS}

Figure 1(a) shows three wide scans, taken from foil samples which differed only in the duration of the cleaning treatment undergone. The Ta peaks in the spectra originate from the sample holders and should be ignored. In addition to the expected carbon, oxygen, and magnesium, the untreated samples contain a significant amount of chlorine. As the spectra in Fig. 1(a) show, magnesium and chlorine are removed by the cleaner. The carbon intensity is reduced by a factor of 2 , indicating that processing oil is removed by the cleaner. Note furthermore that the cleaning treatment of $4 \mathrm{~min}$ does not seem to have more effect on the foil composition than the $30 \mathrm{~s}$ treatment has.

Similar spectra as in Fig. 1(a) were obtained for other lengths of the cleaning time. We determined the peak areas of $\mathrm{Mg} 1 s$ and $\mathrm{C} 1 s$, normalized them on the total $\mathrm{Al} 2 p$ peak areas, and took the resulting ratios as a measure for the $\mathrm{Mg}$ and $\mathrm{C}$ content in the aluminum foils. The dependence of $\mathrm{Mg}$ and $\mathrm{C}$ content on the duration of cleaning treatment is shown in Fig. 1(b). From this figure one can conclude that the result of the cleaning procedure is effectuated in the first two minutes.

Figure 2 clearly shows the extra information one can get from angle dependent measurements. For the untreated aluminum foil, the carbon over aluminum intensity ratio increases as a function of off-axis angle. This means that the carbon forms a layer on top of the aluminum oxide. A rough estimate based on Eq. (1) indicates that the hydrocarbon layer has a thickness in the order of $3 \mathrm{~nm}$. The
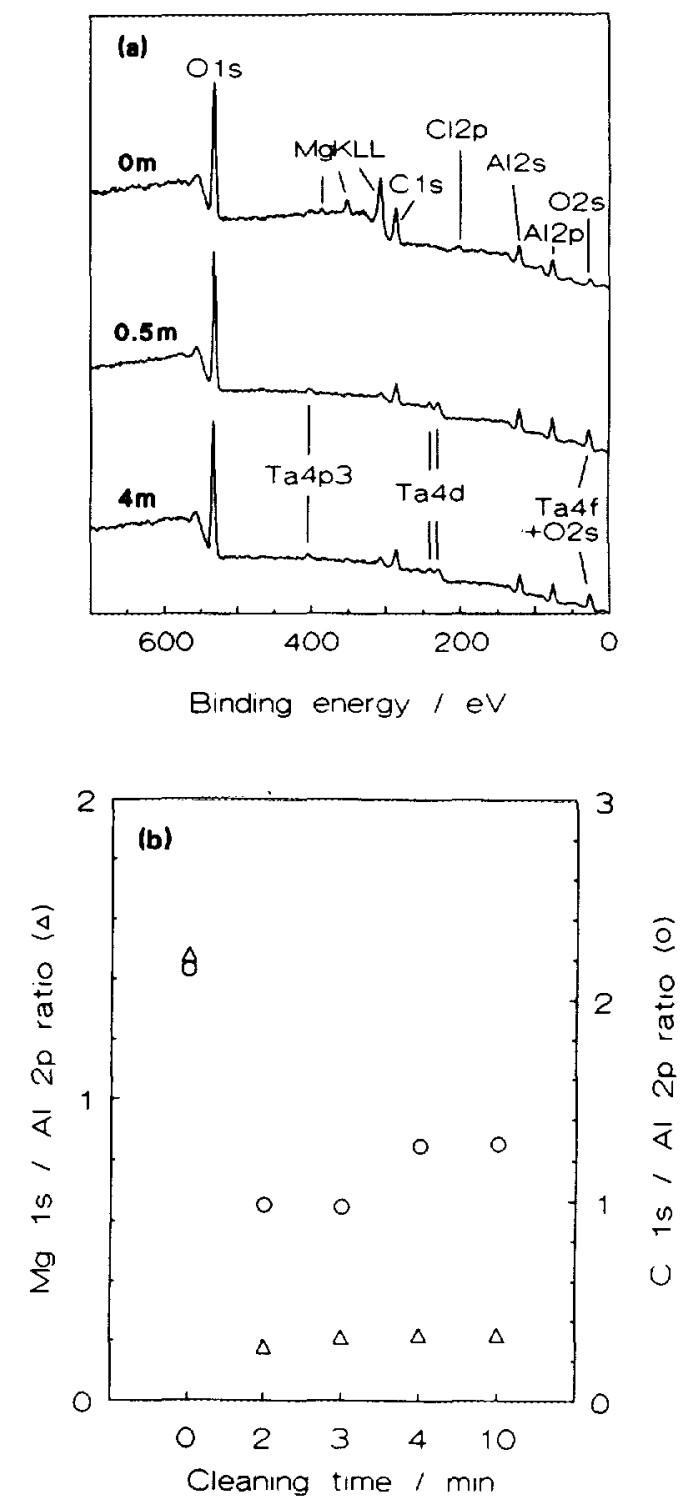

FIG. 1. (a) XPS wide scan of the untreated aluminum foil, and of foils treated with cleaner for 0.5 and $4 \mathrm{~min}$. The Ta signal is due to the sample holder. (b) XPS intensity ratios versus cleaning time for the different contaminants: $\Delta$ is $\mathbf{M g}$, and $O$ is $C$.

angular dependence of the $\mathrm{C} 1 s / \mathrm{Al} 2 p$ intensity ratio decreases dramatically for cleaned foils. As we discuss later, this decreased angular dependence can be largely attributed to increased surface roughness of the foils.

Applying a pass energy of $20 \mathrm{eV}$, it is possible to separate the oxidic and metallic part of the $\mathrm{Al} 2 p$ peak clearly, see Fig. 3. We present the angle dependent intensity ratios of the $\mathrm{Al}^{3+}$ and $\mathrm{Al}^{\circ}$ peaks in Fig. 4, along with a number of theoretical curves based on Eq. (2). Apparently Eq. (2) does not apply. We come back on this in Sec. IV.

\section{B. SIMS}

The upper part of Fig. 5 shows the SIMS spectra of an untreated aluminum foil. The $\mathrm{Al}$ peak at mass 27 dominates the positive SIMS spectrum. Also the peaks at masses $43\left(\mathrm{AlO}^{+}\right), 54\left(\mathrm{Al}_{2}^{+}\right)$and $70\left(\mathrm{Al}_{2} \mathrm{O}^{+}\right)$are attributed to Al-containing ions. The contamination of the surface by 


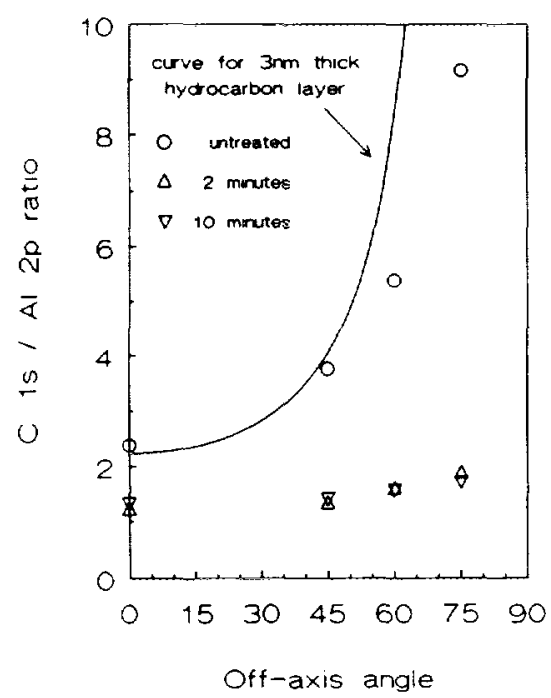

FIG. 2. XPS C $1 s / \mathrm{Al} 2 p$ intensity ratios as a function of off-axis angle, $\mathrm{O}$ : untreated foil, $\Delta$ : foil treated with cleaner for $2 \mathrm{~min}, \nabla$ : treated for $10 \mathrm{~min}$ The curve drawn corresponds to a $3 \mathrm{~nm}$ thick hydrocarbon layer; it is calculated using Eq. (1).

processing oil is visible in the carbon-containing cluster ions $\left(\mathrm{C}_{x} \mathrm{H}_{y}\right)$ in the mass regions 12-15 and 24-26; these signals, however, appear most clearly in the negative SIMS spectra. Contaminants of the untreated $\mathrm{Al}$ foil are $\mathrm{Na}(23$ amu), $\mathrm{Mg}(24), \mathrm{K}(39), \mathrm{Ca}(40), \mathrm{V}(51)$, and Cr (52), where the intensities of sodium and potassium are strongly enhanced by the high ionization probabilities of these elements.

Negative SIMS is more sensitive to the presence of hydrocarbons at the surface than positive SIMS. Characteristic are the peaks at masses $12\left(\mathrm{C}^{-}\right), 13\left(\mathrm{CH}^{-}\right), 24$ $\left(\mathrm{C}_{2}^{-}\right)$, and $25\left(\mathrm{C}_{2} \mathrm{H}^{-}\right)$. The absence of hydrocarbon clusters of higher mass reflects that the processing oil is ali-
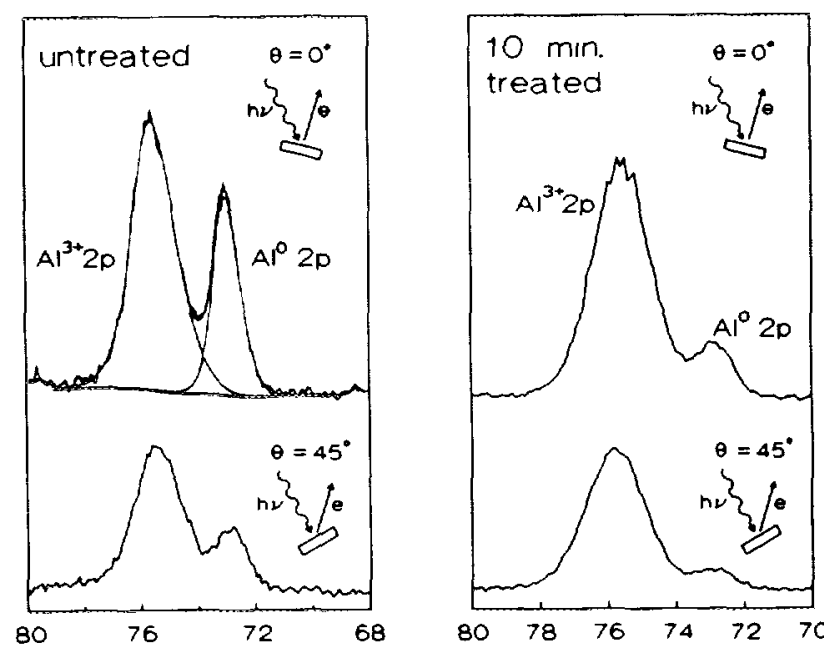

Binding energy / eV

FIG. 3. Al $2 p$ XPS spectra-taken at the indicated off-axis angles-of a foil before (left) and after cleaning for $10 \mathrm{~min}$ (right). These spectra were taken at constant pass energy of $20 \mathrm{eV}$

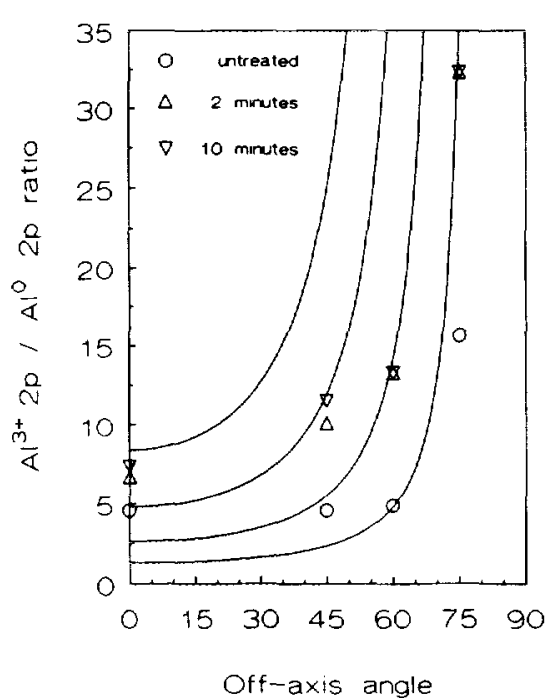

FIG. 4. XPS intensity ratios of the $\mathrm{Al}^{3}+/ \mathrm{Al}^{\mathrm{0}} 2 p$ signals as a function of off-axis angle, $O$ : untreated foil, $\triangle$ : foil treated with cleaner for 2 min, $\nabla$ : treated for $10 \mathrm{~min}$. Also shown are some curves calculated from Eq. (2). Going from top to bottom these curves correspond to oxide layer thicknesses of $7.0,5.6,4.2$, and $2.8 \mathrm{~nm}$.

phatic in nature. Furthermore, the negative SIMS spectrum shows a chlorine contamination; however, one should keep in mind that a low $\mathrm{Cl}$ concentration already gives a high SIMS intensity, due to its high electron affinity.

The lower part of Fig. 5 gives the positive and negative SIMS spectra of an aluminum foil after a cleaning period of $2 \mathrm{~min}$. The negative SIMS spectrum shows that indeed most of the hydrocarbons are removed from the surface by the treatment. Quantification of this reduction is possible by dividing the hydrocarbon intensity by a properly chosen reference characteristic for the substrate, e.g., $\left(\mathrm{C}_{2}^{-}+\mathrm{C}_{2} \mathrm{H}^{-}\right) / \mathrm{AlO}^{-}$. We thus estimate that at least $80 \%$ of the oil contamination is removed. As the foils were exposed to the air after cleaning, a fraction of the carbon results from air exposure. Hence the figure of $80 \%$ reduction probably underestimates the efficiency of the cleaning treatment for removing oil.

Another effect of the treatment is the removal of magnesium, potassium, calcium, and chlorine. Besides the removal of surface contaminants, also new species appear during the cleaning treatment. Clearly visible is the presence of phosphate, as evidenced by the peaks at masses 31 $\left(\mathrm{P}^{+}\right)$and $47\left(\mathrm{PO}^{+}\right)$in the positive spectrum and 31 $\left(\mathrm{P}^{-}\right), 47\left(\mathrm{PO}^{-}\right), 63\left(\mathrm{PO}_{2}^{-}\right)$, and $79\left(\mathrm{PO}_{3}^{-}\right)$in the negative spectrum. Also the amount of chromium ( $52 \mathrm{amu}$ ), manganese ( $55 \mathrm{amu}$ ), and iron ( $56 \mathrm{amu}$ ) at the surface has increased. The evolution of a number of SIMS intensity ratios with cleaning time is given in Fig. 6.

\section{Scanning electron microscopy}

SEM pictures of Au-covered aluminum foils are given in Fig. 7. The images were taken in the secondary electron mode, with the detector at the top-right position of the picture. White, intense features correspond to elevated re-

\section{J. Vac. Sci. Technol. A, Vol. 10, No. 4, Jul/Aug 1992}



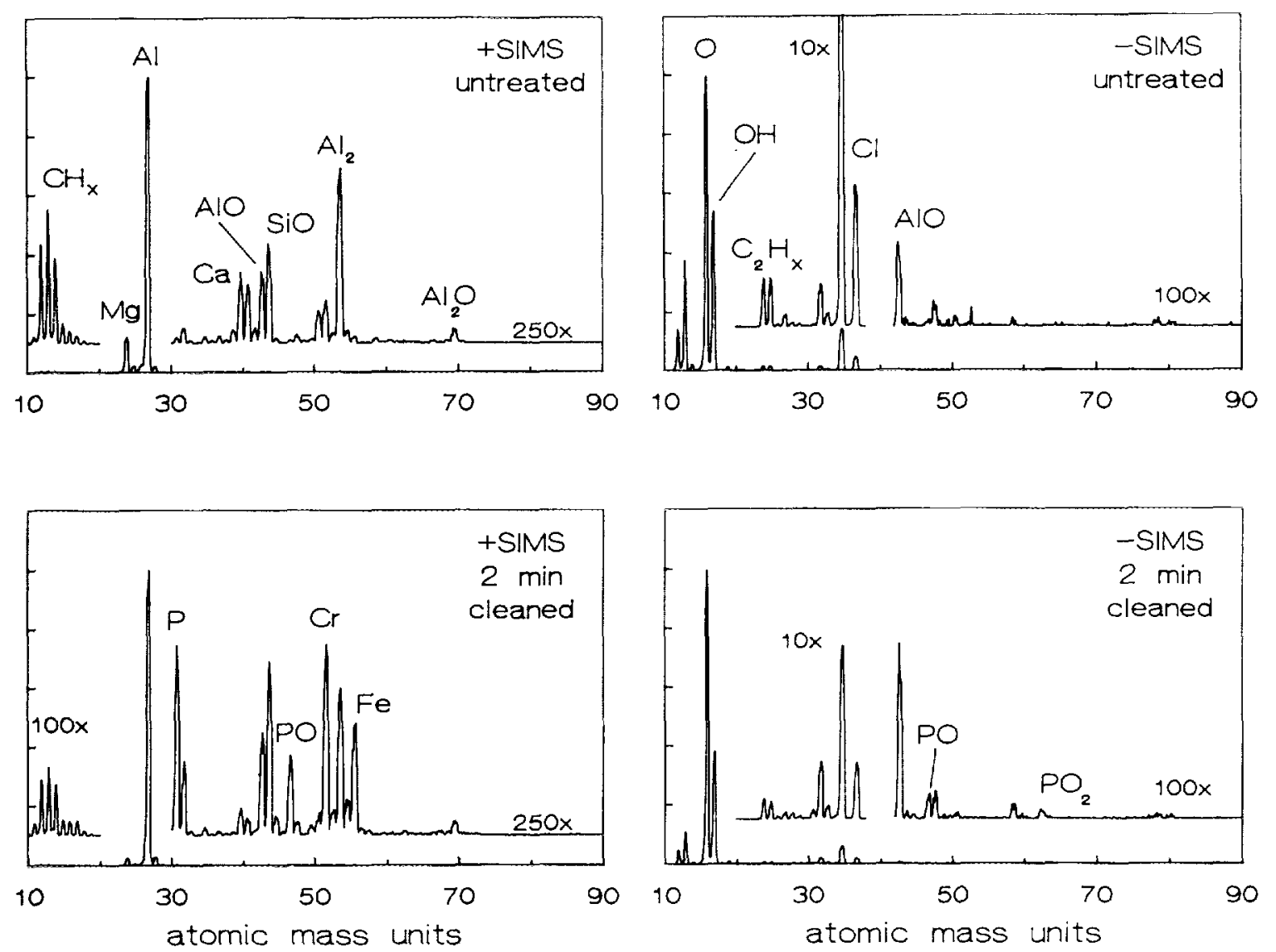

FIG. 5. Positive (left) and negative SIMS spectra (right) of an aluminum foil before (top) and after cleaning for 2 min (bottom).

gions of the sample, while dark features represent deeper regions from which secondary electrons cannot reach the detector.

The SEM picture of the untreated foil clearly exhibits deformations of the surface due to the rolling process. Measurement of the roughness by means of a stylus profile meter revealed that the tracks in Fig. 7(a) correspond to valleys of typically $5 \mu \mathrm{m}$ wide and $1 \mu \mathrm{m}$ deep. Apart from these parallel deformations, the surface appears flat, at least on the micrometer scale of these techniques.

Cleaning has a profound effect on the morphology of the foils, as Fig. 7(b) shows. The sharp edges due to the rolling stage have become much smoother and, in addition, a large number of holes has developed with diameters of typically $0.1 \mu \mathrm{m}$. The depth cannot be determined because the holes are inaccessible to the tip used in stylus profile measurements. The sharp holes correspond to regions which are etched at a faster rate than the surrounding medium. Because (i) we know that the $\mathrm{Al}$ foils contain inclusions rich in $\mathrm{Mg}$, and (ii) both XPS and SIMS indicate that $\mathrm{Mg}$ is rapidly removed by the cleaner, we assign the holes in Fig. 7 (b) to former $\mathrm{Mg}$ inclusions which are etched at a relatively high rate (with respect to aluminum) by the alkaline cleaner.

\section{DISCUSSION}

The most important conclusions from this work, as drawn from Figs. 1(b), 6, and 7 are as follows. (i) Rolled aluminum foils are covered by a deposit of oil residue; the surface region consists of a layer of aluminum oxide, which contains magnesium oxide and a chlorine contamination. The foils exhibit elongated deformations due to the rolling process. Apart from these features the surfaces are relatively smooth on the micrometer scale.

(ii) Cleaning with an aqueous solution of sodium carbonate, sodium phosphates, and surfactants with a $p \mathrm{H}$ of 10 removes most of the oil residue, increases the oxygen content and decreases the $\mathrm{Mg}$ content of the surface region; phosphate is deposited on the surface while at the same time the concentrations of the minor constituents, $\mathrm{Fe}, \mathrm{Cr}$, and $\mathrm{Mn}$ increase. The surface of the foils contains an abundance of small holes with typical dimensions on the order of $0.1 \mu \mathrm{m}$.

We attribute the changes in composition and morphology of the foils to the etching action of the alkaline cleaning solution. The picture that emerges is that an untreated foil has a passivation layer of aluminum oxide, which contains magnesium inclusions (oxidic in the surface region), and a hydrocarbon layer on top. The cleaning removes the oil residue on a time scale of tens of seconds and then starts to etch the surface. Magnesium is etched at a faster rate than the surrounding alumina and magnesium rich areas are converted to the holes that are visible in the SEM pictures of all cleaned foils. The reason that simultaneously minor constituents such as $\mathrm{Fe}, \mathrm{Mn}$, and $\mathrm{Cr}$ enrich at the

J. Vac. Sci. Technol. A, Vol. 10, No. 4, Jul/Aug 1992 

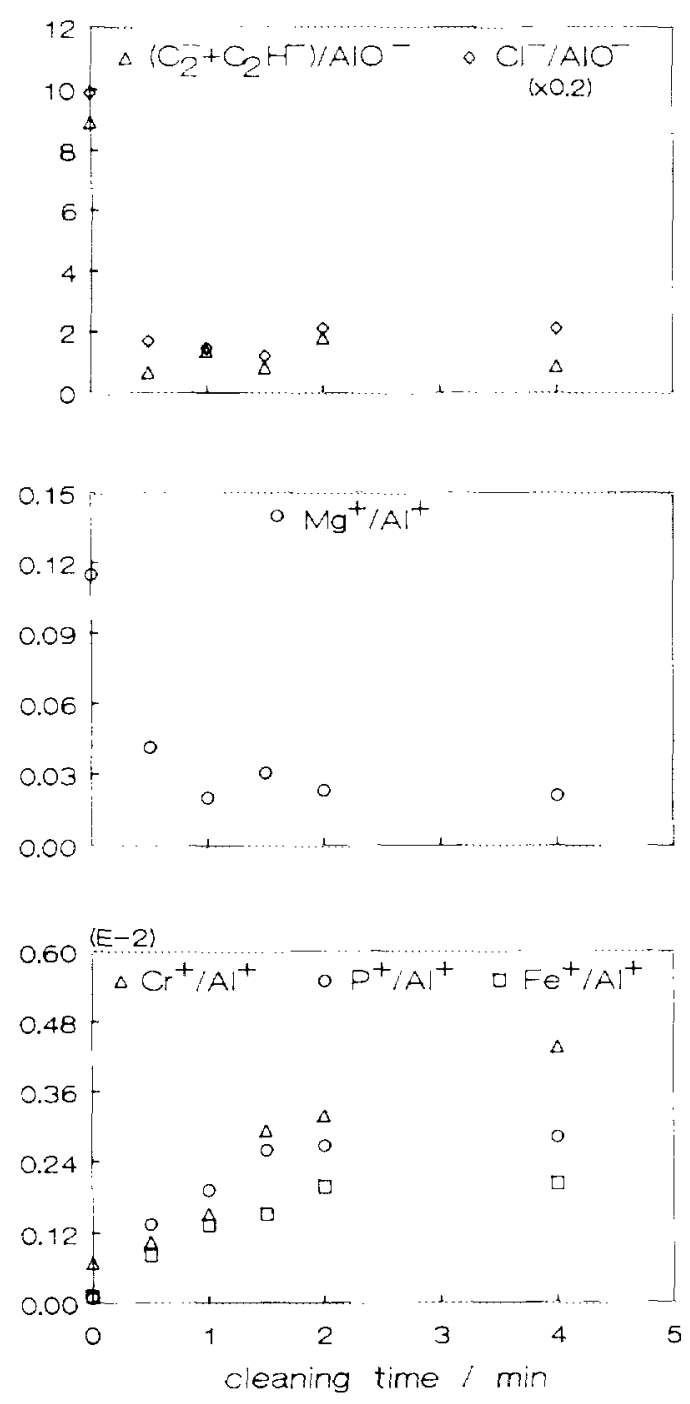

FIG. 6. The variation of characteristic secondary ion intensities with cleaning time (top: negative ions; middle and bottom: positive ions). All intensities are normalized to substrate signals.

surface of the foils, is probably that these elements are less sensitive to etching than $\mathrm{Mg}$ and $\mathrm{Al}$.

The SIMS spectra, recorded under static conditions, refer to the outer layer composition and indicate that the processing oil is effectively removed from the surface after relatively short contact times of $30 \mathrm{~s}$ only. The XPS C $1 \mathrm{~s}$ intensity drops by a factor of 2 , but indicates a higher carbon concentration than the SIMS data do. As XPS probes a layer with a thickness of several nanometers, this technique also detects carbon that may be present below the surface. In this respect the angle dependent XPS data in Fig. 2 are of interest. The $\mathrm{C} 1 s / \mathrm{Al} 2 p$ intensity ratio for the untreated foil increases strongly with increasing offaxis angle, indicating that the aluminum is covered by a hydrocarbon layer. The cleaned foils still contain a significant amount of carbon, however, with an off-axis angular dependence that resembles that of the aluminum. If the morphologies of the foils were the same before and after cleaning, the decreased angular dependence of the $\mathrm{C} / \mathrm{Al}$ intensity ratio would imply that in the treated foils carbon

\section{J. Vac. Sci. Technol. A, Vol. 10, No. 4, Jul/Aug 1992}
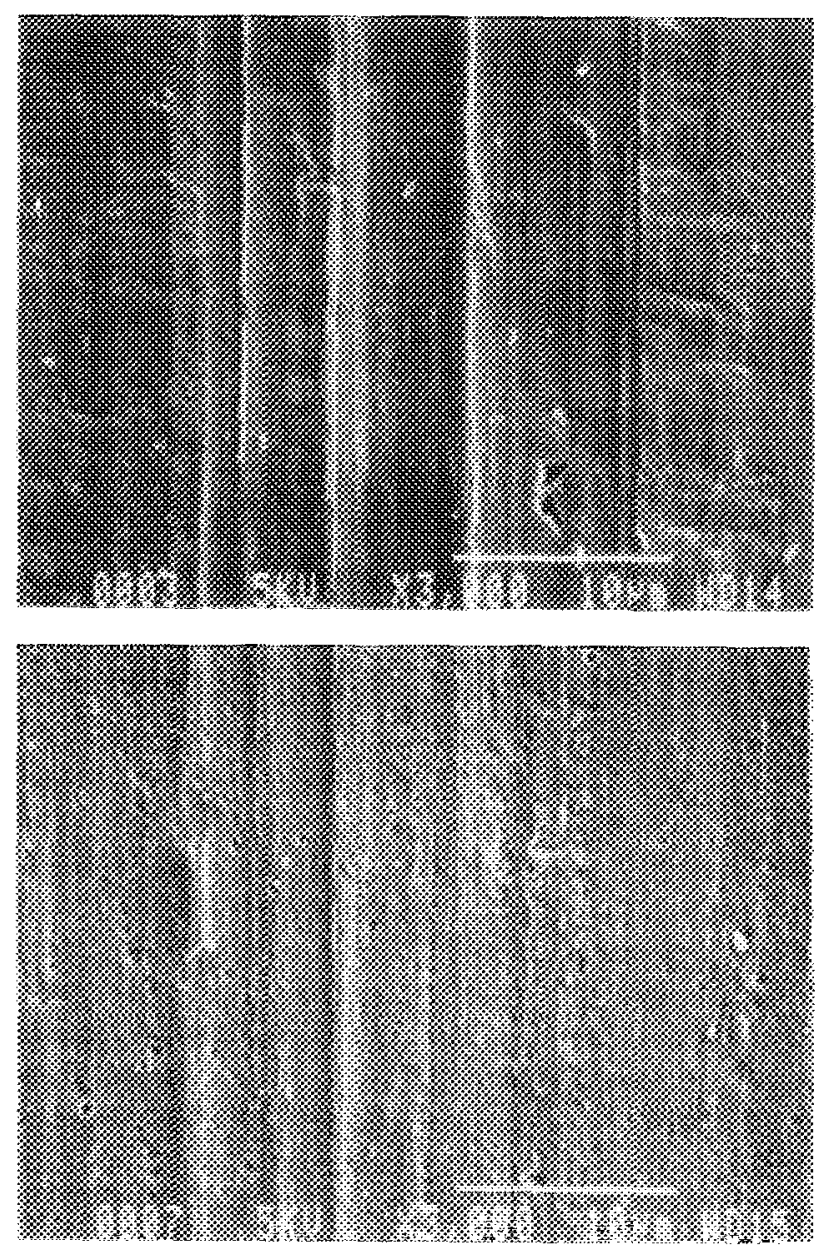

FIG. 7. Secondary electron images of an aluminum foil before (top) and after (bottom) cleaning, taken with the detector in the top right position of the picture.

is mixed with aluminum. However, cleaned Al foils become rougher on the submicron scale and this also causes the angular dependence to be less pronounced. ${ }^{5,6}$

Qualitatively, the spectra suggest that cleaned aluminum foils have a thicker aluminum oxide passivation layer than the untreated foils. Apparently, the adsorbed processing oil inhibits further oxidation of the foils. The angular dependence of the $\mathrm{Al}^{3+} / \mathrm{Al}^{0} 2 p$ XPS intensity ratio gives information about the distribution of oxide and metal. If the oxide forms a well-defined sharp uniform layer, the ratio is given by expression (2). However, Fig. 4 shows that the measured ratios as a function of angle cannot be described by Eq. (2). The deviation of the angular dependence from the ideal behavior expressed in Eqs. (1) and (2) can stem from inhomogeneous composition, a nonuniform thickness of the overlayer, or from surface roughness. In the latter case there is no unique orientation of the surface normal and the off-axis angle varies continuously over the surface. This is certainly an important factor in the angle dependent $\mathrm{C} 1 s / \mathrm{Al} 2 p$ and $\mathrm{Al}^{3+} / \mathrm{Al} 2 p$ XPS intensity ratios for the cleaned foils. With respect to the effect of inhomogeneous surface composition on the angular dependence of XPS intensity ratios it is interesting that, 
according to Barr, ' passivated aluminum foils have been found to expose significant amounts of zero-valent aluminum on their surfaces, which are described as trapped $\mathrm{Al}$ atoms or clusters in the $\mathrm{Al}_{2} \mathrm{O}_{3}$ matrix. The effect of this would indeed be that the $\mathrm{Al}^{3+} / \mathrm{Al}^{0}$ ratio increases less with increasing off-axis angle than Eq. (1) predicts.

Thus, several factors are present which cause the angle dependent $\mathrm{Al}^{3+} / \mathrm{Al}$ intensity ratio to deviate from the ideal expression in Eq. (2). Hence, its application on a single XPS measurement to determine the thickness of the aluminum oxide layer would yield a highly unreliable value. Thickness determinations with XPS should not be carried out without a check whether Eq. (2) is applicable.

The eventual goal of the cleaning procedure is to improve the adhesive properties of the foils for use as a substrate for organic layers. Removal of oil, and the development of surface roughness on the submicron scale will contribute to better adhesion. SIMS reveals that small amounts of phosphate (below the detection limits of XPS) remain on the surface. The deposition of phosphate increases with the time the foil is exposed to the detergent, and seems to stabilize after $2 \mathrm{~min}$. The presence of phos- phates is interesting, because phosphate is known to improve the adhesive properties of aluminum and steel surfaces towards protective coatings. ${ }^{7}$

As to optimizing the contact time between foil and cleaner, it is clear that $30 \mathrm{~s}$ is sufficient to remove the large part of the processing oil from the surface. However, the removal of $\mathrm{Mg}$ which as we believe is directly correlated to the development of surface roughness, and the phosphate content of the surface both stabilize after 1-2 min exposure to the cleaner. The results therefore indicate that the optimum contact time for cleaning should be on the order of a few minutes.

${ }^{\text {a) }}$ Author to whom correspondence should be addressed.

${ }^{1}$ T. L. Barr, J. Vac. Sci. Technol. 14, 660 (1977)

${ }^{2}$ B. R. Strohmeier, Surf. Interface Anal. 15, 51 (1990)

${ }^{3}$ B. R. Strohmeier, Appl Surf Sci 40, 249 (1989).

${ }^{4}$ B. R. Strohmeier, J. Vac. Sci. Technol. A 7, 3238 (1989)

${ }^{5}$ C. S. Fadley, Progr. Solid State Chem. 11, 265 (1976).

'P. L. J. Gunter, A. M. de Jong, H. J. H. Rheiter, and J. W. Niemantsverdriet, Surf. Interface Anal. (in press).

${ }^{7}$ D. Galjaard and A. van Leeuwen, Chemische Oppervlaktebehandelingen van Metalen (Spruyt, van Mantgem en de Does NV, Leiden, 1969), p. 91 (in Dutch) 